\title{
High-speed and High-current Phase Width Modulator Driver for High-power Infrared LEDs
}

\author{
Jye-Chau $\mathrm{Su}^{1}$ and Cheng-Tao Tsai ${ }^{*}$ \\ ${ }^{1}$ Department of Electronic Engineering, National Chin-Yi University of Technology, Taichung 41170, Taiwan \\ ${ }^{2}$ Department of Electrical Engineering, National Chin-Yi University of Technology, Taichung 41170, Taiwan
}

(Received June 21, 2020; accepted October 13, 2020)

Keywords: pulse width modulation (PWM), light-emitting diodes (LEDs)

In this paper, a high-speed and high-current pulse width modulation (PWM) driver for highpower infrared light-emitting diodes (LEDs) is proposed. High-power infrared LEDs have been widely used in applications of distance measurements, in which the LEDs must be driven by a pulse-current driver. The pulse-current driver must have a high pulse current (about $1 \mathrm{~A}$ or more) and achieve high-speed PWM (a pulse width of about 200 ns or less). Because the traditional PWM drivers cannot meet the requirements for testing the performance of highpower and high-speed infrared LEDs, a prototype high-speed and high-current PWM driver is built to overcome this problem. Experimental results verify the performance and the feasibility of the proposed PWM driver for high-power infrared LEDs.

\section{Introduction}

Nowadays, mobile phones, tablets, liquid crystal display (LCD) TVs, and cars use infrared light-emitting diodes (LEDs)..$^{(1,2)}$ With the increasing range of application of 3D sensing technology, the demand for high-power and high-current infrared LEDs is also increasing. The advent of the high-power infrared LEDs has opened up new application areas, especially 3D sensing of mobile phones and distance detection of cars. These applications are mainly driven by pulse currents to generate continuous pulse optical signals. ${ }^{(3-5)}$ When such a pulse light signal comes in contact with a target, data in the form of continuous pulses are produced, which are processed and calculated by a receiver, as shown in Fig. 1. As the measurement distance of the object increases, the required pulse current of the high-power infrared LEDs also increases. (6-8) Therefore, the phase width modulation (PWM) drivers used with high-power infrared LEDs must have sufficient capacity to provide high-current and high-speed pulses.

The driving methods currently used with direct-drive circuits for infrared LEDs can be divided into two types: direct-drive circuits with a DC power supply and those with a signal generator. ${ }^{(9-11)}$ However, the two driving methods cannot meet the high-current and high-speed time requirements of high-power infrared LEDs. The two types of driving circuits are described in detail as follows:

*Corresponding author: e-mail: cttsai@ncut.edu.tw https://doi.org/10.18494/SAM.2021.3020 


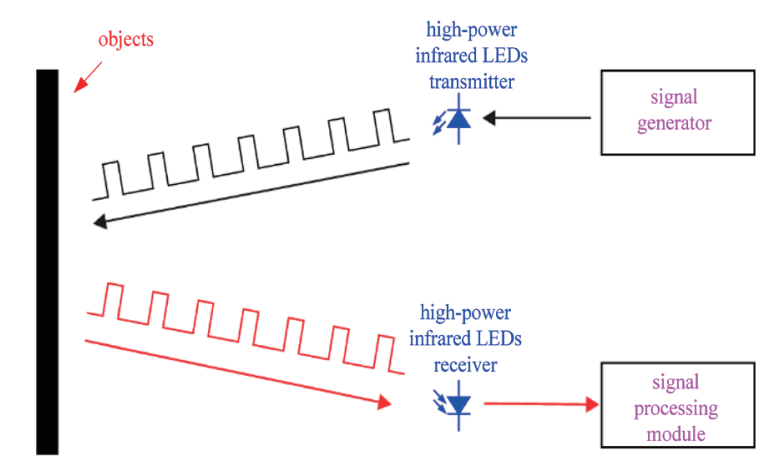

Fig. 1. (Color online) Schematic illustration of distance detection.

\section{Direct-drive circuit with a DC power supply}

A direct-drive circuit with a DC power supply uses a current-limited resistor in series with the high-power infrared LEDs to limit the highest pulse current flowing through the LEDs, as shown in Fig. $2 .^{(12)}$ The advantage of the driving circuit is that the amplitude of the pulse current can easily provide a specific current value ( 1 to $5 \mathrm{~A}$ ). The disadvantage of the driving circuit is that the pulse width of the pulse current cannot be adjusted to less than $200 \mathrm{~ns}$. This results in long rising and falling times of the pulse current, as shown in Fig. 3.

2. Direct-drive circuit with a signal generator

A direct-drive circuit with a signal generator uses a 50 ohms current-limited resistor in series with the high-power infrared LEDs to limit the highest pulse current flowing through the LEDs, as shown in Fig. $4 .^{(13,14)}$ The advantage of the driving circuit is that the pulse-width time of the PWM can be adjusted to as small as $100 \mathrm{~ns}$. The disadvantage of the signal generator is that it can only provide a small current (about $200 \mathrm{~mA}$ ), as shown in Fig. 5.

To overcome the above disadvantages, a high-speed and high-current PWM driver is proposed, as shown in Fig. 6. The advantages of the proposed driver will be detailed in the next section.

\section{Proposed High-speed and High-current PWM Driver}

The proposed high-current and high-speed PWM driver can overcome the disadvantages of the direct-drive circuit with a DC power supply or a signal generator. The high-current and high-speed PWM driver has the advantages of both a DC supply and a signal generator, which can meet the testing requirements of infrared LEDs. This PWM driver can easily adjust the amplitude of the supply current and the pulse width to meet the requirements of infrared LEDs. The operational modes of the high-current and high-speed PWM driver over one switching cycle can be divided into two modes as follows:

\section{$<$ Operational mode $1>$}

When the switch $\left(M_{p}\right)$ is turned on, the energy stored in the snubber capacitor $\left(C_{s}\right)$ will be charged. The current $\left(i_{s}\right)$ flowing through the switch $\left(M_{p}\right)$ is divided into three paths. The first path is $V_{s} \rightarrow R \rightarrow$ high-power infrared LEDs $\rightarrow M_{p} \rightarrow V_{s}$, the second path is $V_{s} \rightarrow C_{s} \rightarrow$ high- 


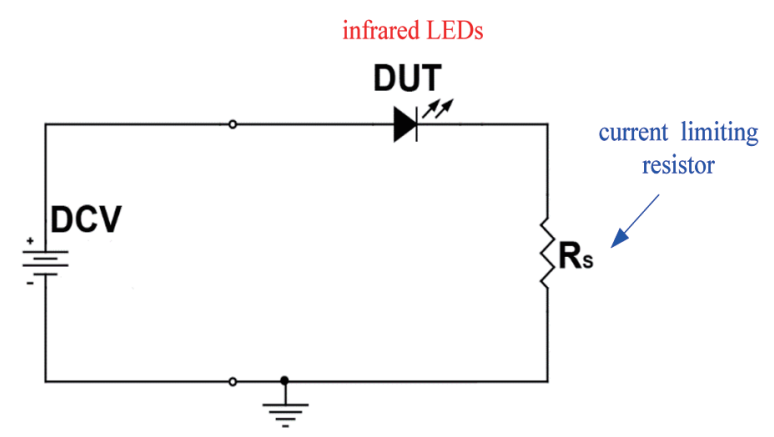

Fig. 2. (Color online) Direct-drive circuit with DC power supply.

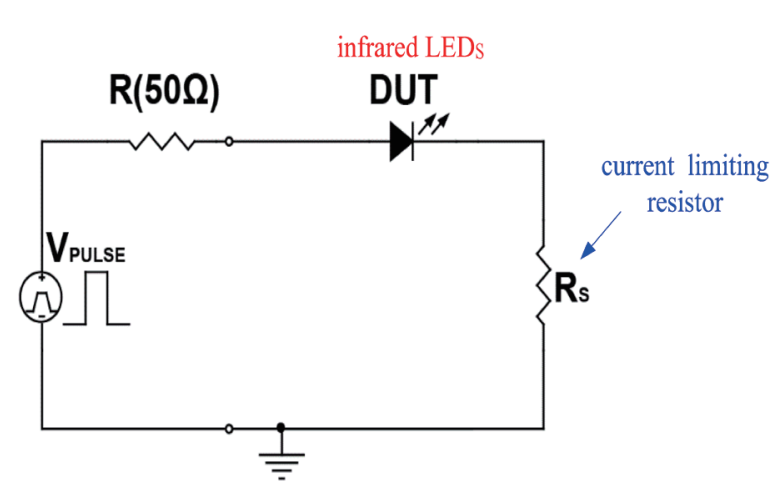

Fig. 4. (Color online) Direct-drive circuit with a signal generator.

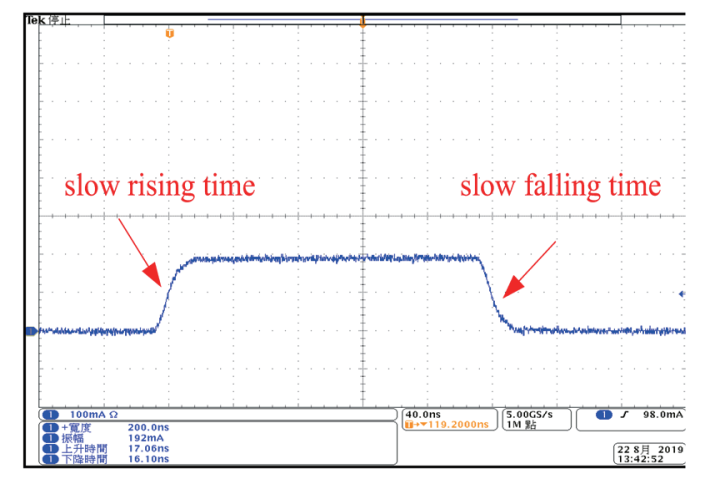

Fig. 3. (Color online) Long rising and falling times of the pulse current for a direct-drive circuit with a DC power supply.

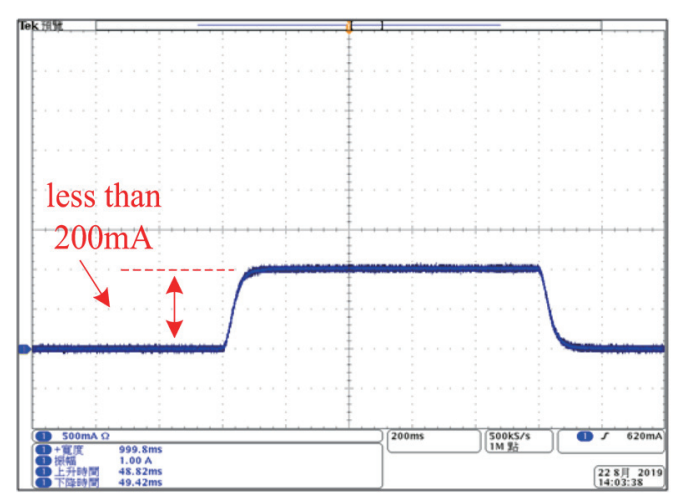

Fig. 5. (Color online) Maximum current (200 mA) provided by a direct-drive circuit with a signal generator.

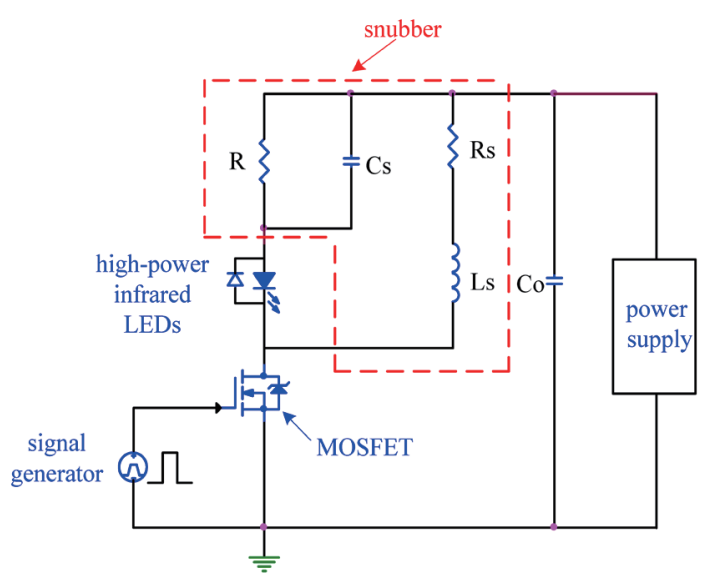

Fig. 6. (Color online) Proposed high-speed and high-current PWM driver.

power infrared LEDs $\rightarrow M_{p} \rightarrow V_{s}$, and the third path is $V_{s} \rightarrow R_{s} \rightarrow L_{s} \rightarrow M_{p} \rightarrow V_{s}$. During this interval, the snubber inductor $\left(L_{S}\right)$ is charged and the infrared LEDs are instantly switched on. The equivalent circuit is shown in Fig. 7(a). 


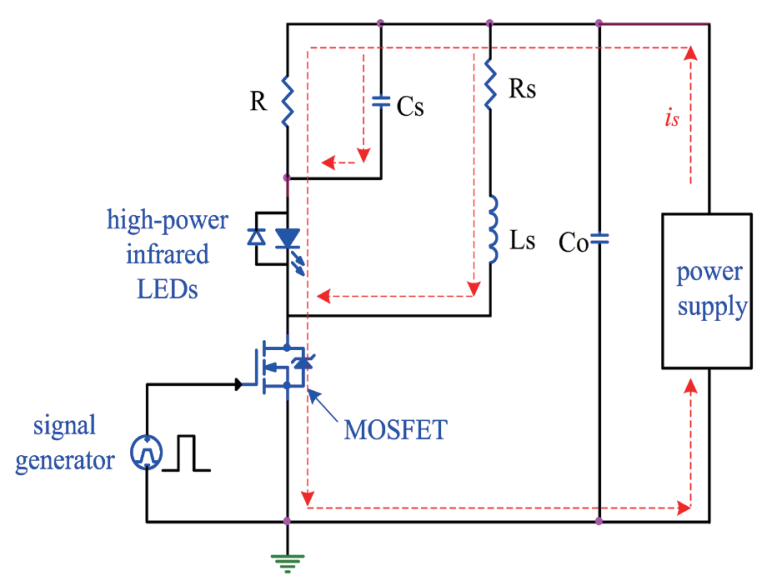

(a)

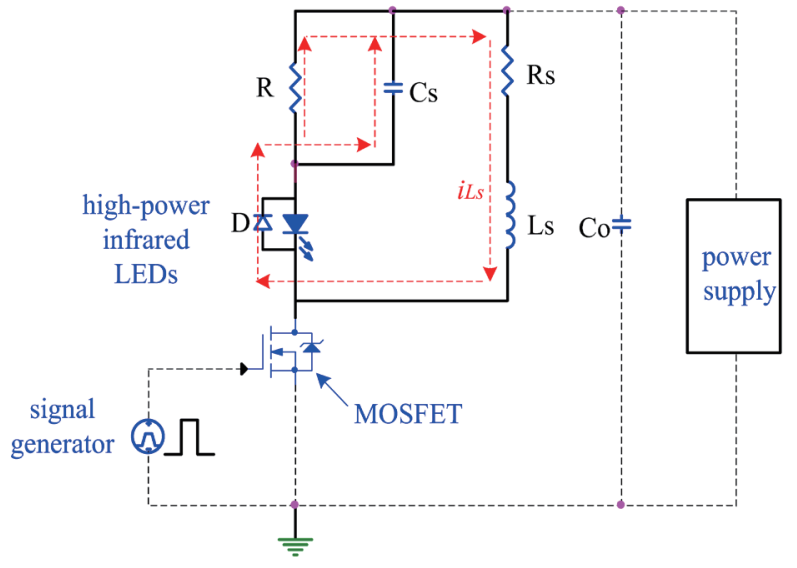

(b)

Fig. 7. (Color online) Equivalent circuits of the proposed high-current and high-speed PWM driver.

\section{$<$ Operational mode $2>$}

When the switch $\left(M_{p}\right)$ is turned off, the energy stored in the snubber inductor $\left(L_{s}\right)$ will be discharged. The discharged current $\left(i_{L s}\right)$ of the snubber inductor $\left(L_{S}\right)$ flows through two paths. One is $R_{S} \rightarrow L_{S} \rightarrow D \rightarrow R \rightarrow R_{S}$ and the other is $R_{S} \rightarrow L_{S} \rightarrow D \rightarrow C_{S} \rightarrow R_{S}$. During this interval, the high-power infrared LEDs are instantly switched off. The equivalent circuit is shown in Fig. 7(b). The operational modes of the proposed high-current and high-speed PWM driver over one switching cycle are thus completed.

\section{Experimental Results}

Figure 8 shows the testing platform of high-power infrared LEDs. It consists of a set of control software, a DC power supply, a signal generator, an oscilloscope, a photometric detector, and a high-current and high-speed PWM driver. The control software and the testing platform of the high-power infrared LEDs are shown in Fig. 9. To verify that the rising and falling times of light-emitting signals that are the same as the pulse widths can be obtained from the proposed high-current and high-speed PWM driver, a Newport 818-BB-21 photometric detector is used to measure high-power infrared LEDs.

Figure 10 shows a comparison between the rising- and falling-time waveforms of the proposed high-current and high-speed PWM driver and the direct-drive circuit with a DC power supply. It can be seen that the proposed PWM driver has short rising and falling times. Figures 11 and 12 show a comparison between the rising- and falling-time waveforms of the light-emitting signals of the high-power infrared LEDs under different pulse widths and pulse currents from the proposed PWM driver, respectively. The pulse current from 1 to $5 \mathrm{~A}$ is provided, and the pulse widths are 100, 120, 140, 160, 180, and $200 \mathrm{~ns}$. It can be seen that by providing suitable pulse widths for the high-power infrared LEDs, a rising time of less than $30 \mathrm{~ns}$ and a falling time of less than $10 \mathrm{~ns}$ can be obtained. Tables 1 and 2 show the rising and 


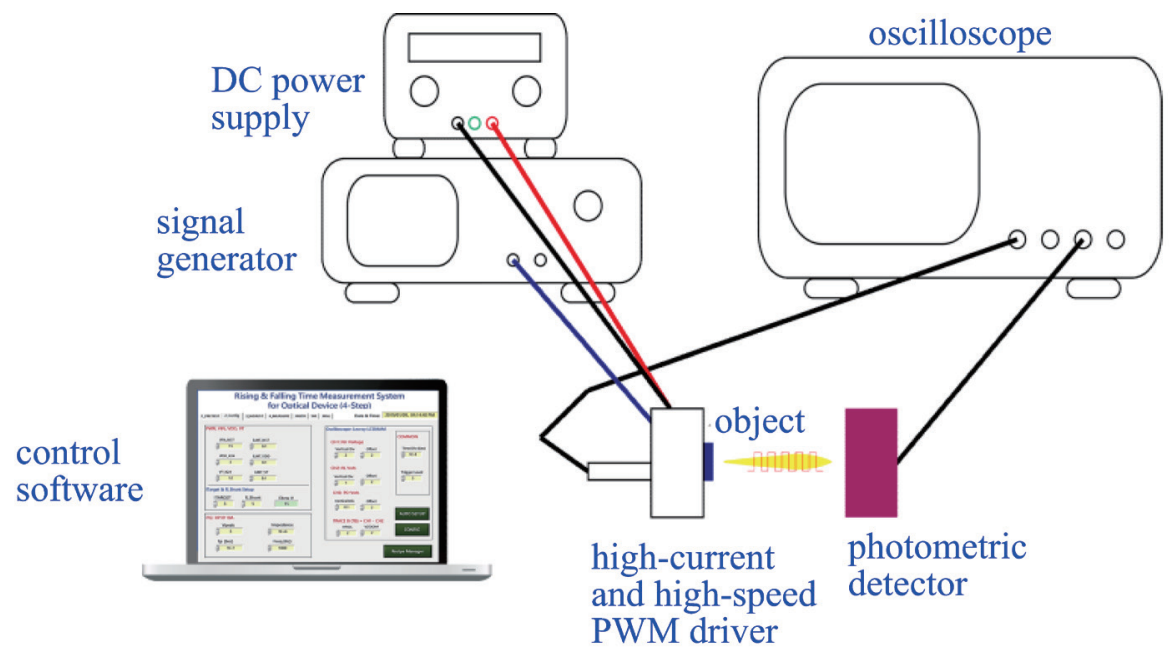

Fig. 8. (Color online) Testing platform of high-power infrared LEDs.

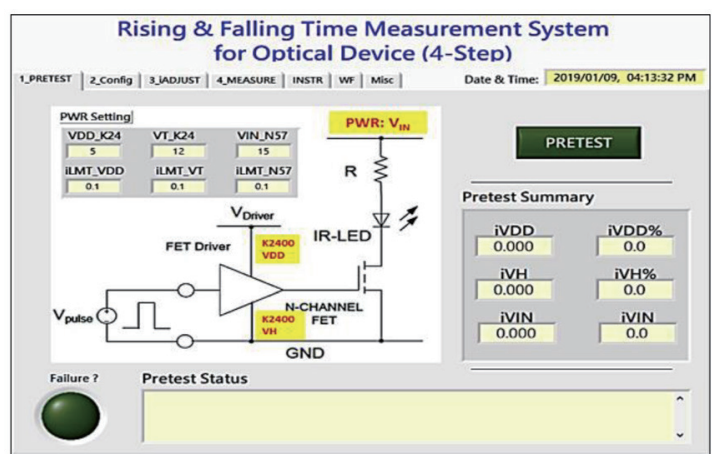

(a)

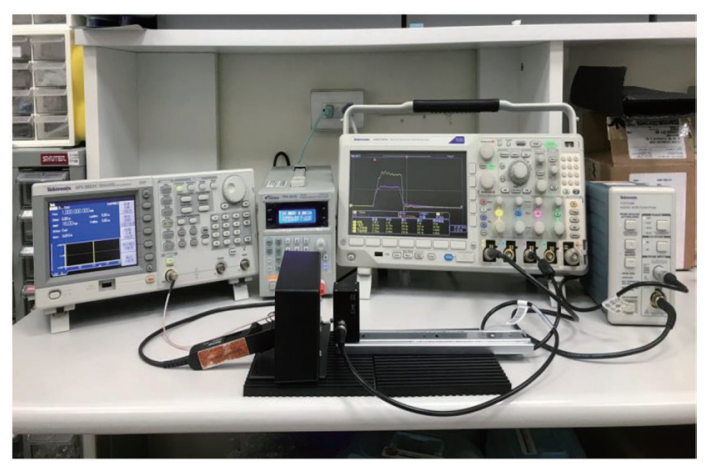

(b)

Fig. 9. (Color online) Testing platform of high-power infrared LEDs: (a) interface of the control software and (b) photograph of the experimental setup.

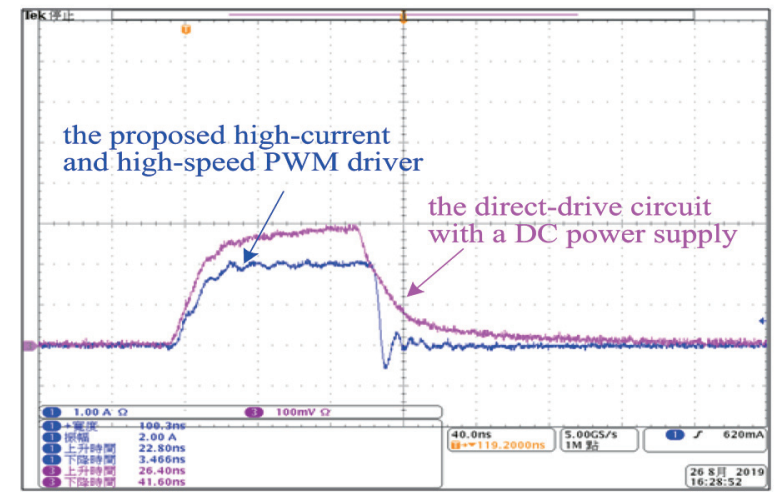

Fig. 10. (Color online) Comparison between the rising- and falling-time waveforms of the proposed high-current and high-speed PWM driver and the direct-drive circuit with a DC power supply. 


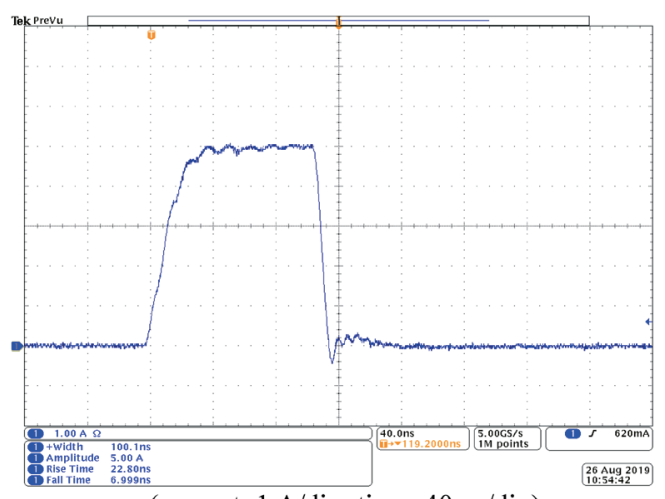

(current: $1 \mathrm{~A} / \mathrm{div}$; time: $40 \mathrm{~ns} / \mathrm{div}$ )

(a)

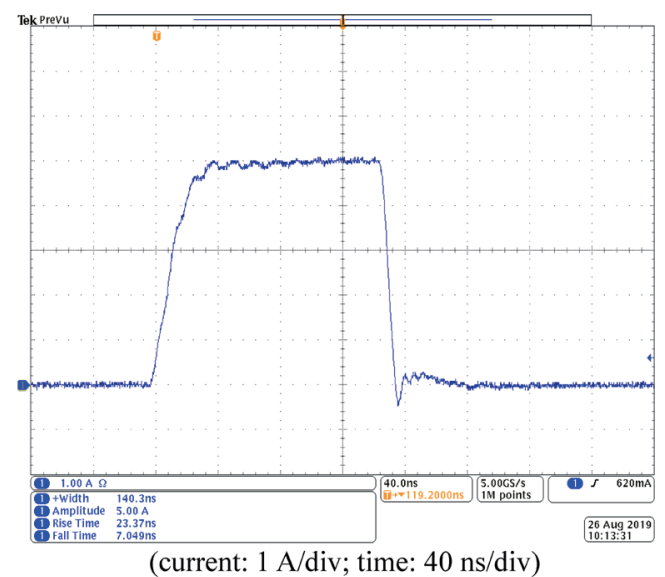

(c)

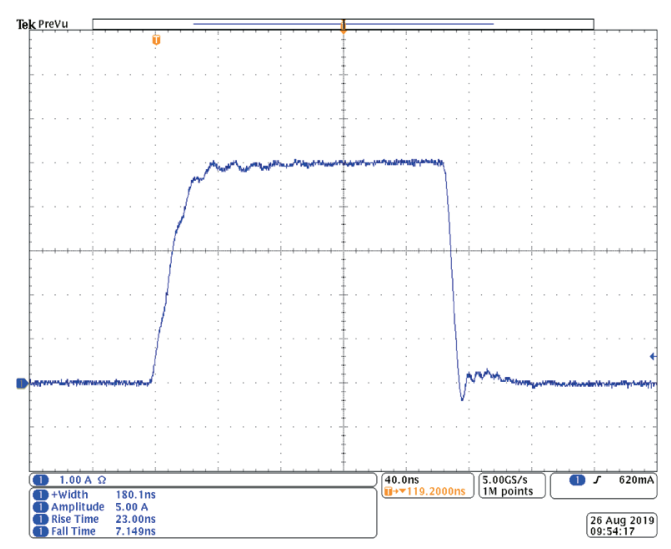

(current: $1 \mathrm{~A} / \mathrm{div}$; time: $40 \mathrm{~ns} / \mathrm{div}$ )

(e)

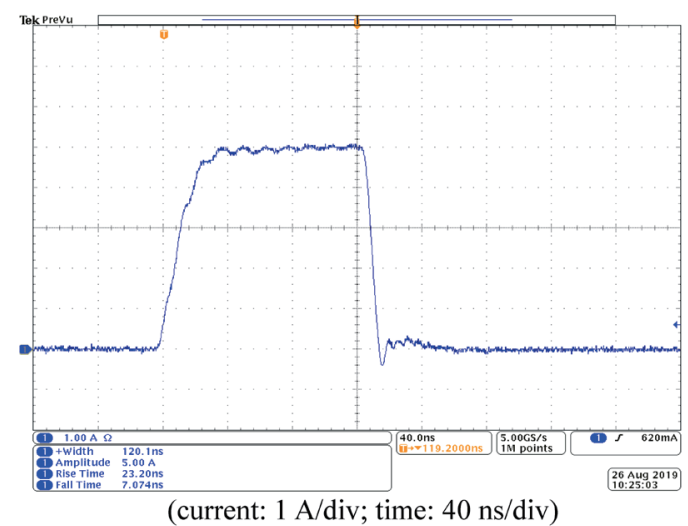

(b)

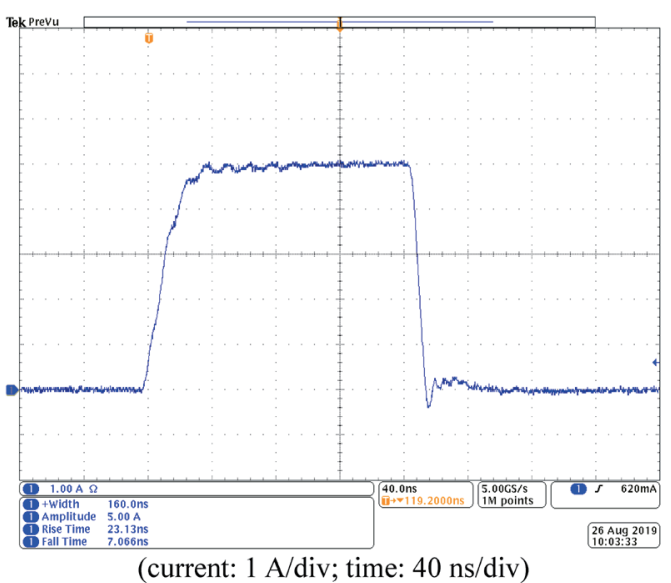

(d)

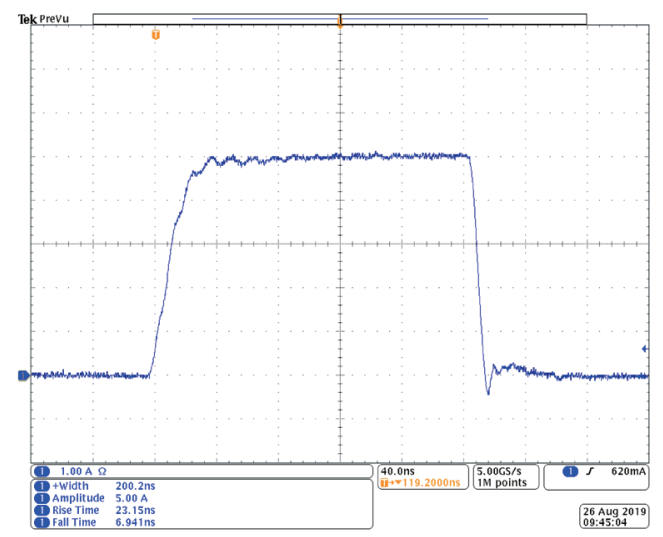

(current: $1 \mathrm{~A} / \mathrm{div}$; time: $40 \mathrm{~ns} / \mathrm{div}$ )

(f)

Fig. 11. (Color online) Comparison between the rising- and falling-time waveforms of the light-emitting signals of the high-power infrared LEDs under the same currents and different pulse widths. (a) Pulse current $=5 \mathrm{~A}$, pulse width $=100$ ns. (b) Pulse current $=5$ A, pulse width $=120$ ns. (c) Pulse current $=5$ A, pulse width $=140$ ns. (d) Pulse current $=5 \mathrm{~A}$, pulse width $=160$ ns. (e) Pulse current $=5 \mathrm{~A}$, pulse width $=180 \mathrm{~ns}$. (f) Pulse current $=5 \mathrm{~A}$, pulse width $=200 \mathrm{~ns}$. 


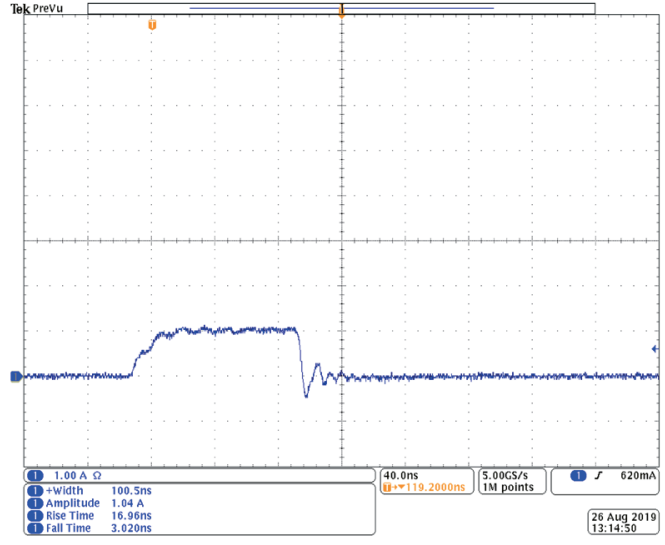

(current:1 A/div; time: $40 \mathrm{~ns} / \mathrm{div}$ )

(a)

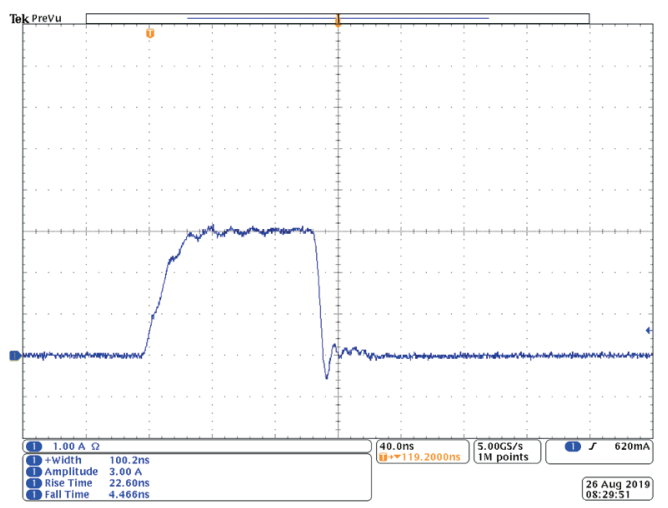

(current:1 A/div; time: $40 \mathrm{~ns} / \mathrm{div}$ )

(c)

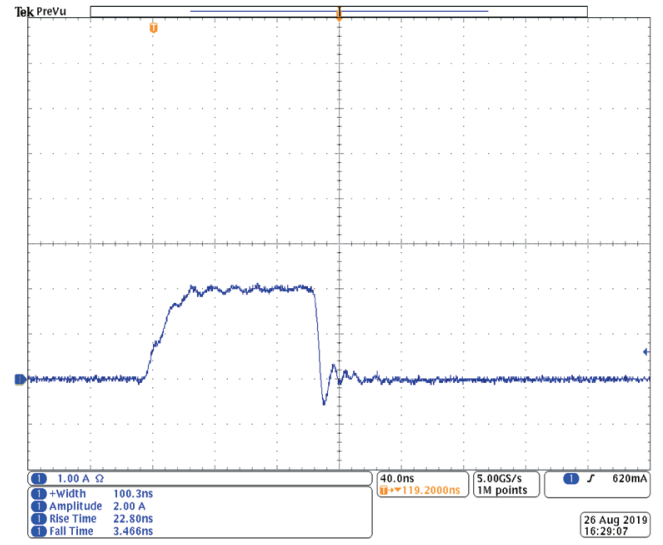

(current:1 A/div; time: 40 ns/div)

(b)

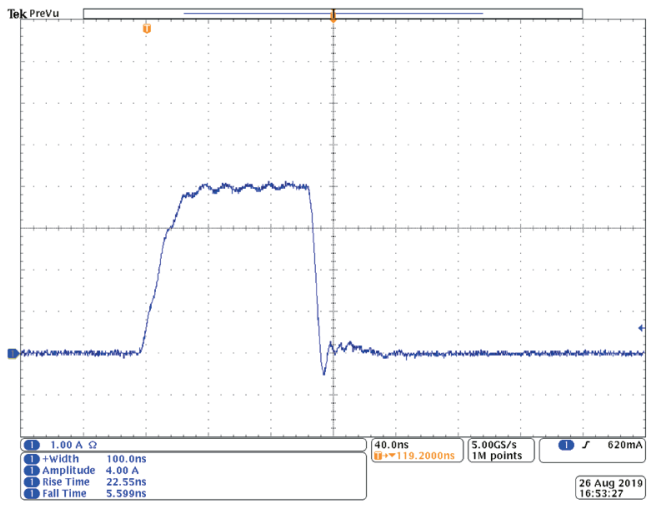

(current:1 A/div; time: $40 \mathrm{~ns} / \mathrm{div}$ )

(d)

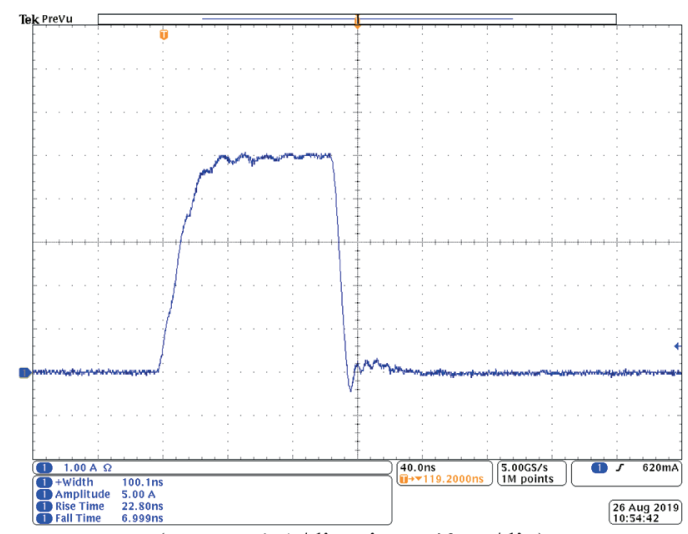

(current:1 A/div; time: $40 \mathrm{~ns} / \mathrm{div}$ )

(e)

Fig. 12. (Color online) Comparison between the rising- and falling-time waveforms of the light-emitting signals of the high-power infrared LEDs under the same pulse widths and different pulse currents. (a) Pulse current $=1 \mathrm{~A}$, pulse width $=100$ ns. (b) Pulse current $=2$ A, pulse width $=100$ ns. (c) Pulse current $=3$ A, pulse width $=100$ ns. (d) Pulse current $=4$ A, pulse width $=100$ ns. (e) Pulse current $=5 \mathrm{~A}$, pulse width $=100 \mathrm{~ns}$. 
Table 1

Rising and falling times under the same pulse currents and different pulse widths.

\begin{tabular}{|c|c|c|c|}
\hline Pulse current (A) & Pulse width (ns) & Rising time (ns) & Falling time (ns) \\
\hline 5 & 100 & 22.80 & 6.999 \\
\hline 5 & 120 & 23.20 & 7.074 \\
\hline 5 & 140 & 23.37 & 7.049 \\
\hline 5 & 160 & 23.13 & 7.066 \\
\hline 5 & 180 & 23.00 & 7.149 \\
\hline 5 & 200 & 23.15 & 6.941 \\
\hline
\end{tabular}

Table 2

Rising and falling times under the same pulse widths and different pulse currents.

\begin{tabular}{lccc}
\hline Pulse width (ns) & Pulse current (A) & Rising time (ns) & Falling time (ns) \\
\hline 100 & 1 A & 16.96 & 3.020 \\
100 & 2 A & 22.80 & 3.466 \\
100 & 3 A & 22.60 & 4.466 \\
100 & 4 A & 22.55 & 5.599 \\
100 & 5 A & 22.80 & 6.999 \\
\hline
\end{tabular}

falling times of the light-emitting signals for the high-power infrared LEDs when the proposed PWM driver provides different pulse widths and different pulse currents, respectively.

\section{Conclusions}

In this study, a high-speed and high-current PWM driver for high-power infrared LEDs has been built and implemented. The PWM driver has the advantages of both a DC supply and a signal generator, enabling it to meet the testing requirements of high-power infrared LEDs. The high-current and high-speed PWM driver can easily adjust the amplitude of the supplied current and the time of the pulse width to meet the testing requirements. From the measurement results, it can be seen that the proposed PWM driver can provide short rising and falling times of the pulse width of less than $30 \mathrm{~ns}$ for the rising time and less than $10 \mathrm{~ns}$ for the falling time, as required for high-power infrared LEDs. Therefore, the proposed PWM driver is suitable for meeting the requirements of high-power infrared LEDs.

\section{Author Contributions}

Both authors contributed to this paper. Jye-Chau Su wrote the paper and Cheng-Tao Tsai contributed to the experimental results.

\section{Conflicts of Interests}

The authors declare that there are no conflicts of interests regarding the publication of this paper. 


\section{References}

1. M. Aykac, F. Bauer, C.W. Williams, M. Loope, and M. Schmand: IEEE Trans. Nuclear Sci. 53 (2006) 1084. https://doi.org/10.1109/TNS.2006.874957

2 Y. H. Kao and T. S. Chu: IEEE Solid-State Circuits 50 (2015) 2665. https://doi.org/10.1109/JSSC.2015.2472599

3 H. Halbritter, C. Jager, R. Weber, M. Schwind, and F. Mollmer: IEEE Photo. Tech. Lett. 26 (2014) 1871. https:// doi.org/10.1109/LPT.2014.2336732

4 S. W. Lee and H. L. Do: IEEE Trans. Power Electron. 32 (2017) 1375. https://doi.org/10.1109/ TPEL.2016.2549029

5 J. Y. Zhu and D. Ding: IEEE Trans. Ind. Appl. 35 (1999) 1406. https://doi.org/10.1109/28.806056

6 J. J. Yun, H. J. Choe, Y. H. Hwang, Y. K. Park, and B. Kang: IEEE Trans. Ind. Electron. 59 (2012) 1808. https:// doi.org/10.1109/TIE.2011.2141095

7 J. W. Kim, J. M. Choe, and J. S. J. Lai: IEEE Trans. Power Electron. 33 (2018) 4306. https://doi.org/10.1109/ TPEL.2017.2722985

8 T. F. Wu, Y. D. Chang, C. H. Chang, and J. G. Yang: IEEE Trans. Power Electron. 27 (2012) 1108. https://doi. org/10.1109/TPEL.2011.2126024

9 S. Jung and G. H. Cho: IEEE Trans. Ind. Electron. 61 (2014) 6710. https://doi.org/10.1109/TIE.2014.2316221

10 L. M. Redondo: IEEE Trans. Plasma Sci. 38 (2010) 2725. https://doi.org/10.1109/TPS.2010.2050495

11 T. J. Liang and J. H. Lee: IEEE Trans. Ind. Electron. 62 (2015) 4492. https://doi.org/10.1109/TIE.2014.2386284

12 W. D. Harris: Proc. Intersociety Energy Conversion Engineering Conf. (IEEE, 1997) 967.

13 I. D. Kim, E. C. Nho, and B. K. Bose: Proc. IEEE Ind. Appl. Conf. (IEEE, 1998) 12.

14 A. R. Vaz and F. L. Tofoli: Proc. Brazilian Power Electronics Conf. (COBEP, 2017) 19.

\section{About the Authors}

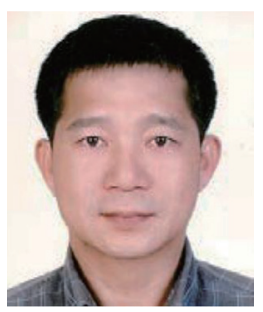

Jye-Chau Su received his B.S. degree in electronic engineering from Tam Chun University, Taipei, Taiwan, in 1991, and his M.S. degree from Fairleigh Dickinson University, USA, in 1998. He is currently working toward a Ph.D. degree at the Graduate Institute of Engineering Science and Technology, National Kaohsiung University, Taiwan. His research interests include converters, inverters, and vehicle power management.

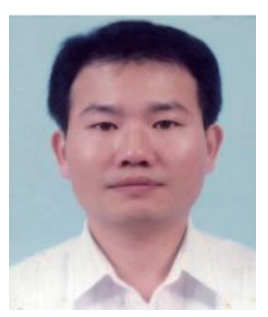

Cheng-Tao Tsai received his B.S. degree in electrical engineering from Feng Chia University, Taichung, Taiwan, in 1991, and his M.S. and Ph.D. degrees from National Chung Cheng University, Chia-Yi, Taiwan, in 2003 and 2008, respectively. Recently, he joined National Chin-Yi University of Technology, Taichung, Taiwan, where he is currently a professor in the Department of Electrical Engineering. His current research interests include the design of switching-mode power supplies, power factor correction technology, and chargers for electric vehicles. 